\title{
Measurement of the amplitude and phase transfer functions of an optical modulator using a heterodyne technique
}

Romstad, Francis Pascal; Birkedal, Dan; Mørk, Jesper; Hvam, Jørn Märcher

Published in:

Proceedings on The 14th Annual Meeting of the IEEE Lasers and Electro-Optics Society

Link to article, DOI:

10.1109/LEOS.2001.969159

Publication date:

2001

Document Version

Publisher's PDF, also known as Version of record

Link back to DTU Orbit

Citation $(A P A)$ :

Romstad, F. P., Birkedal, D., Mørk, J., \& Hvam, J. M. (2001). Measurement of the amplitude and phase transfer functions of an optical modulator using a heterodyne technique. In Proceedings on The 14th Annual Meeting of the IEEE Lasers and Electro-Optics Society (Vol. 1, pp. 34-35). IEEE.

https://doi.org/10.1109/LEOS.2001.969159

\section{General rights}

Copyright and moral rights for the publications made accessible in the public portal are retained by the authors and/or other copyright owners and it is a condition of accessing publications that users recognise and abide by the legal requirements associated with these rights.

- Users may download and print one copy of any publication from the public portal for the purpose of private study or research.

- You may not further distribute the material or use it for any profit-making activity or commercial gain

- You may freely distribute the URL identifying the publication in the public portal 


\title{
Measurement of the amplitude and phase transfer functions of an optical modulator using a heterodyne technique
}

\author{
F. Romstad, D. Birkedal, J. Mork and J.M. Hvam \\ COM, Technical University of Denmark, Building 345V, DK-2800 Kgs. Lyngby, Denmark \\ (phone: +454525 5763, fax: +4545936581, fr@com.dtu.dk)
}

\section{Introduction}

External modulators such as Mach-Zehnder interferometers (MZI) and electroabsorption modulators (EAM) has proven advantageous for reduction of the pulse chirp compared to directly modulated lasers. Even pre-compensation of the pulse dispersion is possible in EAMs [1]. The chirp appearing on the transmitter pulse, being generated by a laser or an external modulator is due to the refractive index modulation following the intensity modulation. Due to temporal phase modulation induced by the change in refractive index additional frequency components are added to the pulse, generating a nontransform limited pulse. The small-signal intensity and refractive index behaviour of the modulator around an operation point can be described by the $\alpha$-parameter [2], being defined as the ratio between the real and imaginary part of the susceptibility for a small externally induced perturbation. Different techniques have previously been used to measure the $\alpha$ parameter in modulators $[3,4]$.

We present a new technique that measures the full amplitude and phase transfer curves of the modulator as a function of the applied bias, from which the small signal $\alpha$-parameter can be calculated. The technique measures the amplitude and phase transfer functions simultaneously and directly, compared to $[3,4]$ where a time-consuming data analysis is necessary to calculate the $\alpha$-parameter and an additional measurement is necessary to estimate the phase [4]. Additionally, the chirp profile for all operation points can be calculated.

Measurement technique and results

The amplitude and phase sensitive technique is based on a heterodyne detection scheme [5]. Figure 1 illustrates the principle in which the component is inserted in one arm of a free space MZI. A small fraction of a $200 \mathrm{fs}$ optical pulse from an optical parametric amplifier (OPA) is diffracted using an acousto-optic modulator (AOM). The diffracted pulse is coupled into and out of the EAM using high NA microscope objectives with an estimated coupling loss of $5 \mathrm{~dB}$. After propagation through the EAM waveguide the pulse is superposed on the non-diffracted reference beam in a beam-splitter (BS). A time delay is included in the reference beam path to overlap the probe and reference pulses in time. A balanced detector measures the two quadratures from the interferometer. The $39 \mathrm{MHz}$ frequency shifting of the probe beam due the diffraction in the AOM and the following superposition with the reference beam give a beating signal with mode spacing of $300 \mathrm{kHz}$, equal to the repetition rate of the optical source. The current from the detector is amplified in a preamplifier before being measured with a lock-in amplifier. The reference signal for the lock-in amplifier is generated by down-mixing the $39 \mathrm{MHz}$ sinusoidal electrical signal with a high harmonic in the synchronous TTL signal from the laser. An appropriate filtering of this signal ensures that the lock-in amplifier detects only the lowest harmonic. By fine-tuning the repetition rate of the system a mode beating below the $120 \mathrm{kHz}$ bandwidth of the dual phase lock-in amplifier can be achieved. The signal measured by the lockin amplifier is proportional to the probe and reference field amplitudes. The signal phase represents the optical phase delay. The probe pulse travelling through the waveguide has a pulse energy of $<500 \mathrm{fJ}$, which was measured to be in the smallsignal regime of the EAM. The reference pulse has $100 \mathrm{pJ}$ of energy. The noise of the system is dominated by the laser intensity noise inherent in the OPA system. A function generator is used to change the reverse bias over the EAM. The bias

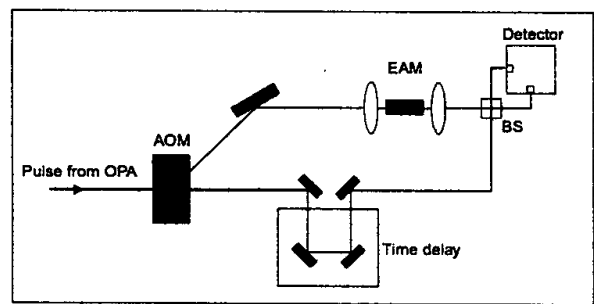

Figure 1. Schematic of the set-up.

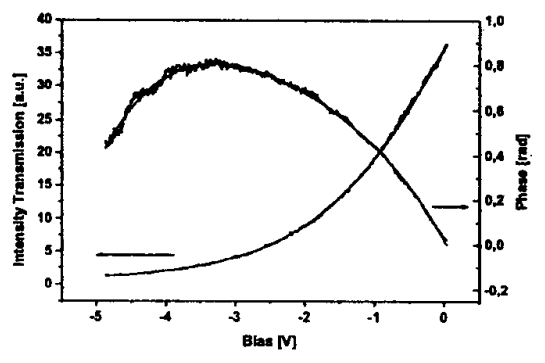

Figure 2. Intensity and phase transfer functions. 


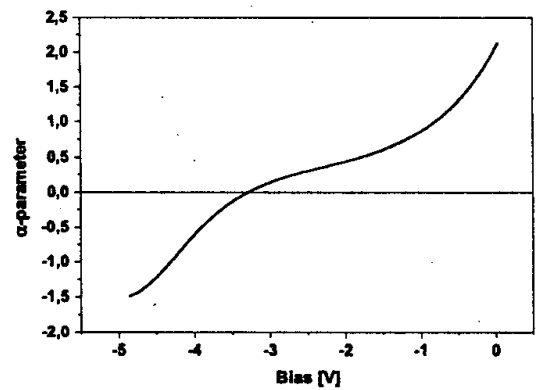

Figure 3: Calculated $\alpha$-parameter from the measured data.

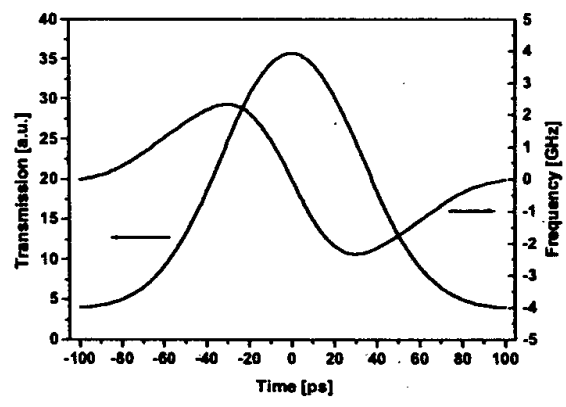

Figure 4. Calculated response of the EAM to a $5 . \mathrm{GHz}$ sinusoidal modulation.

is modulated using a saw-tooth shape with a 0 to $-5 \mathrm{~V}$ swing. The modulation frequency is $55 \mathrm{~Hz}$. The in-phase (X) and outof-phase $(Y)$ component from the lock-in amplifier is recorded on a oscilloscope, triggered by the function generator. Averaging on the oscilloscope is necessary to reduce the noise. From the $X$ and $Y$ components.the relative amplitude transmission (T) and phase $(\phi)$ is calculated, $T=\left(X^{2}+Y^{2}\right)^{1 / 2}$ and $\phi=\operatorname{atan}(Y / X)$, respectively.

The investigated component is a InGaAs/InGaAsP electroabsorption modulator with ten quantum wells. The device length is $200 \mu \mathrm{m}$. The component had an insertion loss of $12 \mathrm{~dB}$ at $1550 \mathrm{~nm}$.

The measured intensity and phase transfer functions for the particular component investigated is shown in Figure 2, together with polynomial fits of the data. The measurement was performed with a TE polarized pulse at $1550 \mathrm{~nm}$. The relative intensity transmission $\left(\mathrm{I}=\mathrm{T}^{2}\right)$ shows, a reduction of the transmission as the reverse bias is applied, as expected. For a voltage sweep from $0 \mathrm{~V}$ to $-5 \mathrm{~V}$ an extinction ratio of $15 \mathrm{~dB}$ is possible. The phase increases for increasing reverse bias until $-3.3 \mathrm{~V}$ where it starts to decrease again. The observed maximum and change of sign of the first derivative of the phase indicates a favourable work point for low-chirp operation.

The $\alpha$-parameter is calculated as

$$
\alpha(V)=-\frac{2 d \phi / d V}{d(\ln (I)) / d V}
$$

Figure 3 shows the $\alpha$-parameter calculated from the polynomial fit of the measured amplitude and phase. As expected, from looking at the phase transfer function in Figure 2, the lowest $\alpha$-parameter is observed at $-3.3 \mathrm{~V}$. Beyond this point the $\alpha$ parameter is negative, and dispersion pre-compensated pulses can be generated.

To show the effect of the intensity and phase modulation at high repetition rate we calculate the response of the component to a $3 \mathrm{~V}_{\mathrm{pp}}, 5 \mathrm{GHz}$ sinusoidal modulation of the reverse bias around $-1.5 \mathrm{~V}$ ( $5 \mathrm{GHz}$ is chosen because it is close to the highest harmonic in a $10 \mathrm{~Gb} / \mathrm{s} \mathrm{NRZ}$ electrical pattern). The response is calculated using the fits of the measured intensity and the phase transfer curves. The extinction ratio is $9.2 \mathrm{~dB}$ and there is a chirp induced frequency generation of $\pm 2.2 \mathrm{GHz}$, corresponding to $\pm 0.017 \mathrm{~nm}$. The pulse is negatively chirped with a blue-shifted leading edge and a red-shifted trailing edge. If instead the offset voltage is set to $-3.3 \mathrm{~V}$ where the $\alpha$-parameter is zero, a reduction of the chimp to $\pm 0.8 \mathrm{GHz}$ is possible (not shown). The extinction ratio is in that case $9.2 \mathrm{~dB}$ and the insertion loss is increased with $5.5 \mathrm{~dB}$.

\section{Conclusion}

We have demonstrated a new amplitude and phase sensitive technique for measuring the full amplitude and phase transfer curves of external modulators as function of applied reverse bias. The technique is faster and more direct than previous techniques. The transfer curves of an electroabsorption modulator are measured, from which a non-constant small signal $\alpha$ parameter is calculated, ranging from 2.1 at $0 \mathrm{~V}$ to -1.5 at $-5 \mathrm{~V}$. An optimum point for generating transform-limited pulses is found at $-3.3 \mathrm{~V}$.

GiGA ApS is acknowledged for providing the components.

11/ F. Devaux and F. Dorgeuille and A. Ougazzaden and F. Huet and M. Carré and A. Carenco and M. Henry and Y. Sorel and J. -F. Kerdiles and E. Jeanney, Photonics Technology Letters, 5, 1288 (1993)

12/ C. H. Henry, Journal of Quantum Electronics, 18, 259 (1982)

/3/ R. A. Saunders and J.P. King and I. Hardcastle, Electronics Letters, 30, 1336 (1994)

14/ F. Devaux and Y. Sorel and J. F. Kerdiles, J. Lightwave Tech., 11, 1937 (1993).

15/ P. Borri and W. Langbein and J. Mork and J.M. Hvam, Optics Communications, 169, 317 (1999) 